\title{
БРИТАНО-БЕЛОРУССКИЕ ПЕРЕГОВОРЫ
}

Аннотация. Дело Скрипалей» окончательно перечеркнуло надежды на улучшение российско-британских отношений в обозримом будущем. Союзники Лондона, проявляя атлантическую солидарность, последовали примеру туманного Альбиона и объявили о выдворении российских дипломатов. К ним присоединились некоторые страны постсоветского пространства и СНГ - Украина, Молдова, Грузия. Минск воздержался от комментариев, однако, 27-28 марта 2018 г. министр иностранных дел Беларуси совершил «исторический»визит в Лондон. Переговоры глав дипломатических ведомств двух стран прошли в позитивном ключе, что подтверждает политику Британии на укрепление отношений со странами постсоветского пространства в условиях крайнего обострения отношений с Россией.

Ключевые слова: внешняя политика Великобритании, британо-белорусские отношения, российско-британские отношения, Брекзит, торгово-инвестиционное сотрудничество.

\section{История развития отношений}

Политический диалог между Великобританией и Республикой Беларусь начал активно развиваться сразу после установления отношений между странами в январе 1992 г. Официальный визит председателя Верховного Совета Беларуси в Великобританию состоялся в декабре 1994 г., а в мае 1995 г. Лондон посетил премьер-министр Республики Беларусь ${ }^{1}$. Одновременно начались интенсивные контакты по линии министерств.

Великобритания была одной из первых стран Евросоюза, которая ратифицировала Соглашение о партнёрстве и сотрудничестве между Беларусью и ЕС от 1995 г. В ноябре 2008 г. состоялся второй визит премьер-министра Республики Беларусь в Великобританию и был приурочен к первому Белорусскому инвестиционному форуму.

Однако с середины 90-х гг. отношения начали постепенно ухудшаться. В 1996 г. по итогам референдума об изменении белорусской конституции был увеличен срок полномочий президента. После президентских выборов 2006 г. Евросоюз ввёл в отношении Республики Беларусь экономические санкции и визовые ограничения для чиновников, включая президента А. Г. Лукашенко. В 2005 г. с лёгкой руки госсекретаря США Кондолизы Райс Республику Беларусь начали называть «последней диктатурой» Европы ${ }^{2}$.

Осенью 2008 г. ЕС приостановил действие санкций в связи с «освобождением политзаключённых и улучшением ситуации с правами человека в Беларуси». Однако после разгона 19 декабря 2010 г. демонстрации в Минске против официальных итогов президентских выборов, Евросоюз возобновил действие ограничительных мер.

«Украинский кризис» 2014 г. и последовавший за ним конфликт на юго-востоке страны стал своеобразным «поворотным моментом» в отношениях Беларуси и коллективного Запа-

(C) Годованюк Кира Анатольевна - старший научный сотрудник Центра британских исследований Института Европы РАН, кандидат политических наук. Адрес: РФ, 125009, Москва, ул. Моховая, д.11, стр. 3. E-mail: kira.godovanyuk@gmail.com

DOI: http://dx.doi.org/10.15211/vestnikieran220188

${ }^{1}$ Посольство Республики Беларусь в Соединённом Королевстве Великобритании и Северной Ирландии. Политические отношения. Режим доступа: http://uk.mfa.gov.by/ru/bilateral_relations/ (дата обращения: 10 апреля 2018).

${ }^{2}$ Astapenia R. Belarus is no longer "Europe's last dictatorship". Available at: https://www.theguardian. com/world/2014/sep/12/belarus-no-longer-europe-last-dictatorship (Accessed: $10^{\text {th }}$ April 2018). 
да. Выступая в качестве посредника по урегулированию вооружённого конфликта, А. Лукашенко внёс вклад в разработку минских договорённостей, что способствовало значительному смягчению позиции Брюсселя в отношении официального Минска.

В 2016 г. Совет министров иностранных дел ЕС отменил ограничения на въезд в отношении 170 граждан Беларуси, включая президента А. Лукашенко, и заморозку активов ${ }^{1}$. Однако в феврале 2018 г. ЕС продли на год (до 28 февраля 2019 г.) некоторые ограничительные меры, в частности, введённое в 2011 г. эмбарго на поставку оружия, а также запрет на въезд в отношении четырёх государственных служащих.

Несмотря на то, что официально Британия не вошла в «нормандский формат» и формально отстранилась от урегулирования ситуации на юго-востоке Украины, в отношениях Лондона и Минска наметилась позитивная динамика. В 2017 г. министры иностранных дел Великобритании и Беларуси обменялись протокольными посланиями по случаю 25-летнего юбилея дипломатических отношений.

В последних докладах «О состоянии прав человека и демократии» (Human Rights and Democracy Report) за 2015 и 2016 г., подготовленных Форин Офисом, Республика Беларусь не была включена в обзор стран, вызывающих обеспокоенность (countries of concern). Более того, наметилась устойчивая тенденция по развитию британо-белорусского диалога и расширению контактов на дипломатическом, торговом и гуманитарном уровнях. В 2017 г. стороны активизировали межпарламентский диалог.

В сентябре 2017 г. в Минск с официальным визитом прибыл государственный министр Форин Офиса по делам Европы и Америки А. Дункан. Стороны наметили пути дальнейшего сотрудничества, в том числе в контексте Брекзита, обсудили белорусско-британское сотрудничество в политической, торгово-экономической и иных сферах, расширение двусторонней договорно-правовой базы, а также региональную повестку ${ }^{2}$.По итогам переговоров была подписана Конвенция об устранении двойного налогообложения в отношении налогов на доходы и капитал и предотвращении уклонения от уплаты налогов. Сегодня Соединённое Королевство является одним из основных торговых партнёров Республики Беларусь.

Наметилась перспектива развития двустороннего военного сотрудничества. Так, 18 декабря 2017 г. в Лондоне состоялись переговоры представителей министерств обороны двух стран, по итогам которых стороны подписали совместное заявление о взаимодействии между военными ведомствами и план военного сотрудничества на 2018 г. Среди ключевых направлений - взаимодействие в области подготовки миротворческих контингентов под эгидой $\mathrm{OOH}^{3}$.

1 EU lifts most sanctions against Belarus despite human rights concerns. Available at: https://www.theguardian.com/world/2016/feb/15/eu-lifts-most-sanctions-against-belarus-despite-human-rights-concerns (Accessed: 10 ${ }^{\text {th }}$ April 2018 ).

2 Посольство Республики Беларусь в Соединённом Королевстве Великобритании и Северной Ирландии. $O$ встрече Министра иностранных дел Беларуси В. Макея с Государственным министром по делам Европы и Америки МИД Великобритании. Режим доступа: http://uk.mfa.gov.by/ru/embassy/news/f12a077fbf3fd691.html (дата обращения: 10 апреля 2018).

3 Минск и Лондон договорились о военном сотрудничестве в 2018 году. Режим доступа: http://tass.ru/mezhdunarodnaya-panorama/4823535 (дата обращения: 11 апреля 2018).

Научно-аналитический вестник ИЕ РАН, 2018, №2 
В течение последних лет стороны сохраняют высокие темпы торгово-экономического сотрудничества. В 2015 г. Великобритания стала третьим по объёмам торговым партнёром Беларуси после России и Украины. В 2017 г. товарооборот между странами составил 2656,6 млн. долл. ${ }^{1}$. Беларусь активно развивает экспорт в Великобританию, так в 2017 г. Минск поставил на туманный Альбион товары на сумму 2407,3 млн. долл. Ведущие экспортные позиции занимают нефтепродукты, продукты перегонки каменноугольной смолы, битумные смеси, удобрения, мебель и др. В 2017 г. общий объем экспорта белорусских услуг в Великобританию достиг 214,9 млн. долл. США. Основные направления - транспортные, компьютерные, деловые и туристические услуги. Компании Беларуси осуществляют разработку программных решений для таких крупных британских компаний как “ВР”, “British Telecom”, "Barclays", «Лондонская фондовая биржа». В Великобритании действуют представительства BNK UK Ltd. (дочерняя структура 3AO «Белорусская нефтяная компания»), OAO «Авиакомпания «Белавиа» и компании «Adani Ltd.UK». Ещё в 2015 г. в Великобритании зарегистрировано представительство ОАО «Банк развития Республики Беларусь». В 2017 г. Великобритания заняла второе место после РФ среди стран-инвесторов в белорусскую экономику (26,6\%). Кроме того, в Беларуси зарегистрировано более 260 предприятий с британским капиталом ${ }^{2}$.

\section{Переговоры министров иностранных дел Беларуси и Великобритании}

После 25-летнего перерыва (последний раз министры иностранных дел Великобритании и Беларуси встречались в 1993 г.) 27-28 марта 2018 г. в Лондон с официальным визитом прибыл министр иностранных дел Республики Беларусь. Главным политическим фоном встречи стала «дипломатическая война» Москвы и Лондона в связи с инцидентом в Солсбери. И хотя переговоры глав дипломатических ведомств не были анонсированы заранее, встреча стала закономерным событием с учётом общего контекста развития политического диалога между Великобританией и Беларусью последних лет.

Наблюдатели попытались связать «неожиданный» визит В. В Макея с решением британской стороны отозвать приглашение С.В. Лаврову посетить Лондон. Однако такие аналогии вряд ли уместны, поскольку Россия и Британия при всех трудностях двусторонней повестки, вряд ли видят Минск в качестве посредника при переговорах. Официальная повестка встречи В. Макея и Б. Джонсона - перспективы двусторонних отношений в контексте актуальной ситуации в европейском регионе в преддверии Брекзита ${ }^{3}$. Основная цель визита В. Макея в Лондон - подтвердить заинтересованность в развитии двусторонних отношений.

1Посольство Республики Беларусь в Соединённом Королевстве Великобритании и Северной Ирландии. Торгово-экономическое сотрудничество. Режим доступа: http://uk.mfa.gov.by/ru/bilateral_relations/trade_economic/ (дата обращения: 11 апреля 2018)

2 Там же

${ }^{3}$ Министерство иностранных дел Республики Беларусь. Об итогах визита Министра иностранных дел Беларуси В.В. Макея в Великобританию. Режим доступа: http://mfa.gov.by/press/news_mfa/d41e8234403a4dfb.html (дата обращения: 11 апреля 2018)

Научно-аналитический вестник ИЕ РАН, 2018, №2 
Лондон и Минск выразили готовность «продвигать инициативы, которые были бы направлены на ослабление напряжённости международной обстановки в регионе» ${ }^{1}$.

Активизация британского направления внешней политики не отменяет главного приоритета Минска - продвижение интеграционных процессов на постсоветском пространстве и сотрудничество с Москвой. За три дня до визита в Великобританию В.В. Макей провёл телефонный разговор с С.В. Лавровым².

По итогам официальных встреч был подписан ряд документов, в том числе соглашение о торгово-экономическом сотрудничестве, которое предусматривает межправительственное взаимодействие для содействия торговле и инвестициям между Беларусью и Великобританией, а также соглашение о взаимодействии между таможенными органами двух стран. Проведены переговоры по широкому спектру политических и экономических вопросов с министром Форин Офиса по делам Европы и Америки А. Дунканом и государственным министром по торговой политике министерства внешней торговли Великобритании Г. Хэндсом.

В. В. Макей также провёл встречу с членами британского парламента, которые входят в межпартийную группу по Беларуси, встретился с принцем Майклом Кентским, который посетил Республику Беларусь в октябре 2016 г. Тогда А. Лукашенко выразил надежду, что в отношениях Великобритании и Беларуси открывается новая страница ${ }^{3}$.

В Лондоне В. В. Макей обсудил с руководством Европейского банка реконструкции и развития реализацию проектов в транспортном, энергетическом, банковско-финансовом и других секторах в рамках Стратегии ЕБРР для Беларуси на 2016-2019 гг. Новая стратегия была принята в 2016 г. «в связи с тем, что Беларусь демонстрирует большую открытость на международном уровне и готовность к обсуждению политической ситуации внутри страны» ${ }^{4}$.

ЕБРР и Беларусь подписали кредитное соглашение (на 42,45 млн. евро) по проекту реконструкции участка второй кольцевой дороги вокруг Минска, которая должна быть завершена к открытию II Европейских игр (пройдут в Беларуси в 2019 г.). Таким образом, общий объем финансовых ресурсов ЕБРР, предоставленных Беларуси за период с 1992 г., превысил 2 млрд евро.

Согласно отчёту Департамента международного развития Великобритании, в 2015 финансовом году Британия через программы международной помощи направила в Беларусь

\footnotetext{
${ }^{1}$ Министерство иностранных дел Республики Беларусь. Об итогах визита Министра иностранных дел Беларуси В.В. Макея в Великобританию. Режим доступа: http://mfa.gov.by/press/news_mfa/d41e8234403a4dfb.html (дата обращения: 11 апреля 2018)

${ }^{2}$ Министерство иностранных дел Республики Беларусь. О телефонном разговоре Министра иностранных дел Беларуси В.Макея с Министром иностранных дел России С. Лавровым. Режим доступа: http://mfa.gov.by/press/news_mfa/e28e3eaa3a37cdc9.html (дата обращения: 11 апреля 2018 ).

${ }_{3}^{3}$ Belarus hopes to open new page in relations with UK. Available at: http://eng.belta.by/president/view/belarus-hopesto-open-new-page-in-relations-with-uk-95275-2016/ eng.belta.by. (Accessed: $11^{\text {th }}$ April 2018).

4 ЕБРР утвердил новую стратегию для Беларуси. Режим доступа: http://www.belta.by/economics/view/ebrrutverdil-novuju-strategiju-dlja-belarusi-209042-2016/ (дата обращения: 11 апреля 2018).
} Научно-аналитический вестник ИЕ РАН, 2018, №2 
почти 3 млн ф. ст. ${ }^{1}$. Основные направления гуманитарных программ Соединённого Королевства для Беларуси - преодоление последствий чернобыльской катастрофы. Великобритания находится на третьем месте по приёму детей из Беларуси, направленных на оздоровление. Так, с 2010 по 2016 гг. в Великобритании прошли реабилитацию 7750 белорусских детей

Наблюдается интерес к Беларуси со стороны британских аналитических центров. Так, во время визита в Лондон глава белорусской дипломатии встретился с представителями Чатэм Хаус, Международного института стратегических исследований, Европейского совета по международным отношениям в рамках круглого стола «Современная Белоруссия и её место в Европе», где изложил позицию Минска по ключевым вопросам международной повестки.

Насыщенный график двухдневного визита В.В. Макея в Лондон свидетельствует о том, что Минск и Лондон заинтересованы в наращивании темпов политического диалога и торгового сотрудничества в среднесрочной и долгосрочной перспективе.

\section{Выводы:}

1. В условиях отчуждения России и Запада, формирования антироссийского лагеря по принципу «кто не с нами - тот против нас» Беларусь не присоединилась к дипломатическим демаршам стран - союзниц Великобритании. Между тем приезд главы белорусской дипломатии в Лондон призван продемонстрировать независимость внешней политики Минска от Москвы.

2. С политической точки зрения визит В.В. Макея в Лондон - сигнал белорусских элит о готовности продолжать курс на укрепление долгосрочных конструктивных отношений с западными партнёрами после многих лет политического и санкционного давления. Минск рассчитывает, что Великобритания обеспечит продвижение политических и торгово-экономических интересов Республики Беларусь на европейском пространстве. Кроме того, потенциал британо-белорусских торговых отношений продолжает оставаться высоким, сохраняются перспективы расширения торгово-инвестиционного сотрудничества в ближайшие годы.

3. Лондон последовательно укрепляет двусторонние отношения со странами постсоветского пространства - ближайшими соседями России, крайне обостряя отношения с Москвой. Так, Великобритания позиционирует себя как один из ключевых союзников Украины, активно поддерживает и финансирует демократические преобразования в стране. Стратегия Великобритании в отношении Минска - расширение торговоинвестиционного и гуманитарного сотрудничества. Лондон планирует задействовать

\footnotetext{
${ }^{1}$ Department for International Development Annual Report and Accounts 2016-17, p. 142. Available at: https://www.gov.uk/government/uploads/system/uploads/attachment_data/file/625548/DFID-Annual-Report-andAccounts-2016-17.pdf. (Accessed: 12 $2^{\text {th }}$ April 2018).

2 Посольство Республики Беларусь в Соединённом Королевстве Великобритании и Северной Ирландии. Гуманитарное сотрудничество. Режим доступа :http://uk.mfa.gov.by/ru/bilateral_relations/cultural/(дата обращения: 12 апреля 2018).
} 
амбиции Белоруссии в продвижении «миротворческой повестки» для расширения британо-белорусского военного сотрудничества, в том числе в рамках операций под эгидой ООН.

4. Между тем развитие политического диалога Лондона и Минска не отменяет главный внешнеполитический приоритет Беларуси - продвижение интеграционных процессов на постсоветском пространстве со ставкой на союз с Россией.

\section{Список литературы}

ЕБРР утвердил новую стратегию для Беларуси. Режим доступа: http://www.belta.by/economics/view/ebrr-utverdil-novuju-strategiju-dlja-belarusi-209042-2016/ (дата обращения: 11 апреля 2018).

Министерство иностранных дел Республики Беларусь. Об итогах визита Министра иностранных дел Беларуси В.В. Макея в Великобританию. Режим доступа: http://mfa.gov.by/press/news_mfa/d41e8234403a4dfb.html (дата обращения: 11 апреля 2018).

Министерство иностранных дел Республики Беларусь. О телефонном разговоре Министра иностранных дел Беларуси В.Макея с Министром иностранных дел России С. Лавровым. Режим доступа: http://mfa.gov.by/press/news_mfa/e28e3eaa3a37cdc9.html (дата обращения: 11 апреля 2018).

Минск и Лондон договорились о военном сотрудничестве в 2018 году. Режим доступа: http://tass.ru/mezhdunarodnaya-panorama/4823535 (дата обращения: 11 апреля 2018).

Посольство Республики Беларусь в Соединённом Королевстве Великобритании и Северной Ирландии. Политические отношения. Режим доступа: http://uk.mfa.gov.by/ru/bilateral_relations/ (дата обращения: 10 апреля 2018).

Посольство Республики Беларусь в Соединённом Королевстве Великобритании и Северной Ирландии. О встрече Министра иностранных дел Беларуси В. Макея с Государственным министром по делам Европы и Америки МИД Великобритании. Режим доступа: http://uk.mfa.gov.by/ru/embassy/news/f12a077fbf3fd691.html (дата обращения: 10 апреля 2018).

Посольство Республики Беларусь в Соединённом Королевстве Великобритании и Северной Ирландии. Торгово-экономическое сотрудничество. Режим доступа: http://uk.mfa.gov.by/ru/bilateral_relations/trade_economic/ (дата обращения: 11 апреля 2018).

Посольство Республики Беларусь в Соединённом Королевстве Великобритании и Северной Ирландии. Гуманитарное сотрудничество. Режим доступа : http://uk.mfa.gov.by/ru/bilateral_relations/cultural/(дата обращения: 12 апреля 2018).

\section{References}

Astapenia R. Belarus is no longer "Europe's last dictatorship". Available at: https://www.theguardian.com/world/2014/sep/12/belarus-no-longer-europe-last-dictatorship (Accessed: 10 ${ }^{\text {th }}$ April 2018).

Belarus hopes to open new page in relations with UK. Available 
at: http://eng.belta.by/president/view/belarus-hopes-to-open-new-page-in-relations-with-uk-952752016/ eng.belta.by. (Accessed: $11^{\text {th }}$ April 2018).

Department for International Development Annual Report and Accounts 2016-17, p. 142. Available at: https://www.gov.uk/government/uploads/system/uploads/attachment_data/file/ 625548/DFID-Annual-Report-and-Accounts-2016-17.pdf. (Accessed: 12 ${ }^{\text {th }}$ April 2018).

EBRR utverdil novuyu strategiyu dlya Belarusi (EBRD adopted new strategy for Belarus). Available at: http://www.belta.by/economics/view/ebrr-utverdil-novuju-strategiju-dlja-belarusi209042-2016/ (Accessed: $11^{\text {th }}$ April 2018).

EU lifts most sanctions against Belarus despite human rights concerns. Available at: https://www.theguardian.com/world/2016/feb/15/eu-lifts-most-sanctions-against-belarus-despitehuman-rights-concerns (Accessed: $10^{\text {th }}$ April 2018 ).

Ministerstvo inostrannyh del Respubliki Belarus'. Ob itogah vizita Ministra inostrannyh del Belarusi V.V. Makeya v Velikobritaniyu. (The Ministry of Foreign Affairs of the Republic of Belarus. About the results of the visit of the Minister of Foreign Affairs of Belarus V. Makey to Great Britain) Available at: http://mfa.gov.by/press/news_mfa/d41e8234403a4dfb.html (Accessed: $11^{\text {th }}$ April 2018)

Ministerstvo inostrannyh del Respubliki Belarus'. O telefonnom razgovore Ministra inostrannyh del Belarusi V.Makeya s Ministrom inostrannyh del Rossii S. Lavrovym. (The Ministry of Foreign Affairs of the Republic of Belarus. About the phone conversation between the Minister of Foreign Affairs of Belarus and the Minister of the Russian Federation S. Lavrov) Available at: http://mfa.gov.by/press/news_mfa/e28e3eaa3a37cdc9.html (дата обращения: 11 апреля 2018)

Minsk i London dogovorilis' o voennom sotrudnichestve v 2018 godu (Minsk and London agreed on the military cooperation in 2018). Available at: http://tass.ru/mezhdunarodnayapanorama/4823535 (Accessed: $11^{\text {th }}$ April 2018).

Posol'stvo Respubliki Belarus' v Soedinyonnom Korolevstve Velikobritanii i Se-vernoj Irlandii. Politicheskie otnosheniya. (Embassy of the Republic of Belarus to the United Kingdom of Great Britain and Northern Ireland Political Relations). Available at: http://uk.mfa.gov.by /ru/bilateral_relations/ (Accessed: 10 ${ }^{\text {th }}$ April 2018).

Posol'stvo Respubliki Belarus' v Soedinyonnom Korolevstve Velikobritanii i Se-vernoj Irlandii. O vstreche Ministra inostrannyh del Belarusi V. Makeya s Gosudar-stvennym ministrom po delam Evropy i Ameriki MID Velikobritanii. (Embassy of the Republic of Belarus to the United Kingdom of Great Britain and Northern Ireland About the meeting of the Minister of Foreign Affairs of Belarus V. Makey with the Minister of State for Europe and the Americas of Foreign Office). Available at: http://uk.mfa.gov.by/ru/embassy/news/f12a077fbf3fd691.html (Accessed: 10 ${ }^{\text {th }}$ April 2018).

Posol'stvo Respubliki Belarus' v Soedinyonnom Korolevstve Velikobritanii i Se-vernoj Irlandii. Torgovo-ehkonomicheskoe sotrudnichestvo. (Embassy of the Republic of Belarus to the United Kingdom of Great Britain and Northern Ireland Economic and trade cooperation). Available at: http://uk.mfa.gov.by/ru/bilateral_relations/trade_economic/ (Accessed: $11^{\text {th }}$ April 2018)

Posol'stvo Respubliki Belarus' v Soedinyonnom Korolevstve Velikobritanii i Se-vernoj Irlandii. Gumanitarnoe sotrudnichestvo. (Embassy of the Republic of Belarus to the United King- 
dom of Great Britain and Northern Ireland Cooperation in the humanitarian sphere). Available at : http://uk.mfa.gov.by/ru/bilateral_relations/cultural/(Accessed: 12 ${ }^{\text {th }}$ April 2018).

\section{UK-Belarus negotiations}

Author. Godovanyuk K., PhD (Political Sciences), Senior Research Associate at the Center for British Studies, Institute of Europe Russian Academy of Sciences. Address: 11-3, Mokhovaya str., Moscow, Russian Federation, 125009. E-mail: kira.godovanyuk@ gmail.com

Abstract. The "spy poisoning" case buried hope for improving UK-Russia relations in the foreseeable future. London's allies in the Atlantic region took the decision to expel Russian diplomats in solidarity with Foggy Albion. The diplomatic "flash mob" was joined by post-soviet and CIS countries such as Ukraine, Moldova and Georgia. The official Minsk didn't make any statement on the case. Meanwhile the minister of foreign affairs of the Republic of Belarus paid a "historic" visit to London on March 27-28 2018. The negotiations went positively which confirms the UK policy of strengthening ties with the post-soviet countries while spoiling them with Russia. tion.

Keywords: UK foreign policy, UK-Belarus, UK-Russia, Brexit, trade and investment coopera-

DOI: http://dx.doi.org/10.15211/vestnikieran220188 